\title{
REPRESENTAÇÕES DE SALVADOR NA LITERATURA BRASILEIRA CONTEMPORÂNEA: POR UM MODELO DE GEOPOÉTICA URBANA
}

\author{
Licia Soares de Souza ${ }^{1}$
}

\begin{abstract}
Resumo: Este texto mostra as bases de um projeto apresentado ao CNPQ para renovação de bolsa de produtividade em pesquisa. O objetivo é o de analisar formações geopoéticas (R. BOUVET) de uma série de narrativas romanescas ambientadas na cidade de Salvador, suscetíveis de construir uma memória longa, com base na recuperação de linguagens oriundas de blocos memoriais em circulação na semiosfera (I. LOTMAN) urbana da Bahia. Nesse sentido, busca-se compor um corpus de romances, produzidos a partir dos anos 1980 até os dias atuais que tenham a cidade de Salvador como cenário. Pensa-se em proceder ao levantamento e à averiguação de obras que inscrevam o espaço urbano soteropolitano na rede estética nacional, que reflete as grandes contradições de uma modernização que insiste na exclusão social, onde já existem exemplos representando outras metrópoles como Rio de Janeiro, Recife, São Paulo, Porto Alegre, entre outras. No presente texto, a ênfase é posta na obra de Inês Pedrosa, A eternidade e o desejo (2008) que põe em confronto espaços de violência da cidade antiga e da cidade moderna, vista através dos sermões do padre Antonio Vieira. Quer-se flagar o trabalho de mobilidade cultural apto a manifestar as transformações que ocorrem nos espaços urbanos soteropolitanos.
\end{abstract}

Palavras chave: Geopoética urbana. Salvador. Memória longa. Semiosfera. Mobilidade cultural. Inês Pedrosa.

\section{REPRESENTATIONS OF SALVADOR IN CONTEMPORARY BRAZILIAN LITERATURE: FOR A MODEL OF URBAN GEOPOETICS}

\begin{abstract}
This text depicts the basis of a project presented to CNPQ- National Council for Scientific ant Technological Development- in order to renew research financing. Its aim is to analyse poetical formations (R. BOUVET) in narrative series in the city Salvador. These series can build a long memory dealing with memorial blocs that circulate in the urban semiosphery (I. LOTMAN) of Bahia. In this manner, we wish to compose a corpus of contemporary novels (from the 1980' untill now) with Salvador as scenary. We intend to investigate the works that show the big contradictions of modernization that insist on keeping social exclusions as depicted in others
\end{abstract}

\footnotetext{
${ }^{1}$ UFba, CNPq.
} 
novels of Rio de Janeiro, Recife, São Paulo and Porto Alegre. In this text, we will emphasize one work of Inês Pedrosa, A eternidade e o desejo (2008), that confronts violent spaces in the old and the modern city that are described through Antonio Vieira's sermons. We want to catch the work of cultural mobility that is able to manifest the transformations going on in urban space of Salvador.

Key Words: Urban geopoetic. Salvador. Long memory. Semiosphery. Cultural mobility. Inês Pedrosa.

\section{Questão de pesquisa}

No âmbito dos estudos sobre as relações entre os espaços territoriais nas literaturas das Américas, desenvolvidos nos grupos ao qual participamos ${ }^{2}$, opta-se por capturar discursos e imagens que retratam uma cidade, caminho este que está lidando com imaginários sociais que podem ser construídos sobre um centro urbano determinado. Uma cidade é objeto de múltiplos discursos e olhares. O enfoque que nosso grupo La Traversée privilegia, o da Geopoética urbana, coloca a história cultural urbana na ordem do dia. Ele permite a emergência de uma metaforização dinâmica, apta a revelar sensações, sentimentos, valores, modos de vida, e formas de resistência, imbricados em uma teia urbana que se revela produtora de memórias curtas e longas, prontas a documentar realística e artisticamente o modo de existência de uma cidade.

Neste contexto, a intenção passou a ser a de um trabalho sobre as representações da cidade de Salvador, em romances da segunda metade do século XX e dos primeiros anos do século XXI. A Literatura brasileira tem apresentado imagens contemporâneas do urbano em cidades como o Rio de Janeiro, São Paulo, Recife, Porto Alegre, entre outras (PESAVENTO, 2002). Muitas dessas imagens foram apresentadas em projetos anteriores, cujas

\footnotetext{
${ }^{2}$ Grupo de pesquisas "Questões de hibridação cultural nas Américas", criado em 1995 e coordenado por Zilá Bernd (Diretório de pesquisa Cnpq); Équipe de Recherche «Mémoires, Territoires, Identités» ERIMIT, do Institut des Amériques da Université de Haute Bretagne, Rennes 2, coordenado por Rita OlivieriGodet; GT Relações Literárias Interamericanas da ANPOLL, coorden ado por Haydée Ribeiro Coelho.; FIGURA, (LA TRAVERSÉE) Universidade do Québec em Montreal, coordenado por Bertrand Gervais.; GIRA, Groupe Interdisciplinaire de Recherche sur les Amériques, coordenado por Frédéric Lesemann e Jean-François Côté.
} 
REPRESENTAÇŌES DE SALVADOR NA LITERATURA BRASILEIRA CONTEMPORÂNEA: POR UM MODELO DE GEOPOÉTICA URBANA

temáticas permitiam refletir as cidades em transformação, como a obra Cidade de Deus, por exemplo³.

Salvador conheceu uma ampla representação nos romances de Jorge Amado entre os anos 1930 e 1970. Segundo Albuquerque Jr. (1999), Amado e Caymmi foram responsáveis pela instituição de um outro Nordeste, não contemplado pela geração modernista de 1930. Estes puseram em cena um Nordeste barroco, reconstituído pelos territórios existenciais dos negros desterrados da África, em constante fusão com os territórios coloniais de uma elite escravocrata que começava a se desestruturar diante das imposições de mudança dos modos de produção capitalista. Uma potencialidade metafórica foi acionada, apta a transmitir as sensibilidades do viver em cidade, como geografia mítica da hagiografia africana, de um mundo popular de artistas de rua, de um mundo de cultura insubmissa, representada nas vozes de um povo desassistido em uma sociedade desigual: prostitutas, meninos de rua, estivadores, marinheiros, malandros, pais e mães-de-santo, entre outros. Os negros e os mestiços foram vistos como porta-vozes de uma resistência ao "materialismo burguês" (ALBUQUERQUE Jr. 1999, p. 223), circulando saberes aptos a resgatar a existência histórica de uma Bahia lírica, com gente criando beleza em uma terrível miséria.

A literatura brasileira, como já foi exposto (SOUZA, 2009), tomou em seguida um caminho de "ficção impura", pós-1964, que pintou a violência do estado, lançando mão de vários álibis discursivos no tratamento referencial da situação política gerada por uma ditadura militar. Colocando uma história de opressão, ligada ao campo semântico da violência, no seio do realismo político que vinha caracterizando a produção artística da época, a literatura brasileira foi articulando uma corrente caracterizada por realismo brutal ou feroz (CÂNDIDO, 1989) 4 . Muitos autores abandonaram a tendência literária de retratar o jaguncismo guerrilheiro, fusão ideológica de conselherista, sertanista e cubanista, e voltaram-se para o realismo feroz da

\footnotetext{
${ }^{3}$ Vide os livros oriundos de nossos projetos anteriores (SOUZA, 2009, 2010, 2013).

${ }^{4}$ Nas cidades, o naturalismo acostumou os leitores com grupos de malandros e de mulatas lascivas, cujas peripécias e atributos sensuais não constituíam um perigo para a sociedade. Mas, a partir dos anos 1990, os escritores e cineastas aproveitaram o embrião narrativo de Rubem Fonseca, que já entrevia a perspectiva conflitante que a violência real projetaria na moderna arte nacional (BISPO, 2009, 304), para dar conta de uma representação de grupos de bandidos sociais, geralmente negros, que ultrapassariam as formações ideológicas da malandragem, para expressarem suas revoltas diante das classes mais abastadas, com armas sofisticadas nas mãos.
} 
urbanidade, apontando para a existência de personagens, vindos de origens diversas, do meio rural ou urbano, confinados nas favelas, e que passaram a se chamar quadrilheiro, como nos exemplos de Cidade de Deus e Elite da Tropa (SOUZA, 2009, 2010, 2013).

Estima-se que a obra de Jorge Amado, com o encantamento da visibilidade e da dizibilidade dos amores e valentias nos mercados populares, na Baía de Todos os Santos, nos terreiros de candomblé e nos casarões coloniais, não dava mais conta do meio urbano de uma Salvador, modificada pela industrialização dos anos 1970. Esta Salvador tinha substituído os centros urbanos do sudeste como polo receptor dos migrantes que fugiam das secas do sertão; passou então a abrigar inúmeras comunidades ${ }^{5}$ e uma população de quase três milhões.

Em dois trabalhos (SOUZA, 2015, 2014) expusemos as diferenças entre a caracterização e os modos de existência das crianças representadas em Capitães de Areia (1937) e Cidade de Deus (1997). Tais textos transpareceram o feixe semântico e mítico em torno da temática da infância, indicando os ideais de inocência e pureza que caracterizam o início de uma existência. As crianças de Amado, abandonadas nas ruas de Salvador, perdem seu mundo de pureza em busca de mecanismos de sobrevivência, mas nutrem sentimentos e valores de solidariedade entre eles e os adultos negros, representantes do candomblé. As crianças de Paulo Lins, entretanto, tem sua inocência comprometida sob o jugo dos coroneis do tráfico de drogas como Zé Miúdo/Pequeno. São iniciadas no mundo do crime organizado, treinadas para matar, sem valores de amizade e de respeito por outrem. Concluimos, nesses trabalhos, que a obra de Amado indicou as anomalias de uma sociedade de exclusão que permitia o abandono de crianças nas ruas, como se estivesse prevendo que a situação pioraria se não houvessem políticas de inclusão com distribuição de renda, visando a qualidade de vida da população.

Por outro lado, existe uma cartografia da cidade em que é comum aparecer, nos romances de Jorge Amado, a divisão em cidade alta e cidade baixa, evocando a clivagem econômica, social, cultural e racial, divisão esta que colabora com a visão de cidade misteriosa e labiríntica ligada por becos e

\footnotetext{
${ }^{5}$ A designação "favela" sempre foi considerada própria do Rio de Janeiro. Em Salvador, falou-se muito tempo em "invasão", mas o termo "comunidade" é o que caracteriza recentemente as zonas mais pobres e problemáticas do contorno urbano da cidade.
} 
ladeiras. Há dois tipos de cidades baixas ${ }^{6}$ e dois tipos de cidades altas ${ }^{7}$. Este espaço urbano vivo já possuía, na época, uma grande variabilidade de relações, podendo ser visto como um palimpsesto, de difícil apreensão. Sua configuração, modelada pelas transformações do aburguesamento progressivo da cidade alta, embelezada e ajardinada, foi contrastando com os velhos casarões que ainda abrigavam hábitos coloniais vistos como ultrapassados.

Nesse contexto, Jorge Amado, membro do partido comunista, empreenderia uma crítica aos valores burgueses, criando uma ficção eivada de várias tensões entre comportamentos malandros, crenças afro-brasileiras seculares e manifestações culturais populares nascidas nas ruas e nos territórios de exclusão "que deviam ser resgatadas para a dizibilidade do país e da região (Nordeste).” (ALBUQUERQUE Jr., 1999, p. 216). Mostrou a formação dos grupos de malandros que ainda amavam sua cidade, transformando-a em parceira de luta, e que ainda possuíam um senso de humanidade, com muitos códigos de solidariedade para se protegerem.

Nosso projeto visa a compor, então, um corpus de romances, produzidos a partir dos anos 1980 até os dias atuais que tenham a cidade de Salvador como cenário. Busca-se proceder ao levantamento e à análise de obras que inscrevam o espaço urbano soteropolitano na rede estética nacional que reflete as grandes contradições de uma modernização que insiste na exclusão social.

Quer-se flagrar a herança da estética amadiana, estampando formas de tradições, lendas, cantos e cerimônias que chegaram ao Novo Mundo a partir do poder da memória, com recuperação de "vestígios" (traces, BERND, 2013) que a história foi incapaz de configurar em todas suas redes relacionais. Quer-se, por outro lado, observar como a massa de excluídos, que passa da

\footnotetext{
6 "Existe uma cidade baixa dos bancos e do comércio atacadista - que tende aliás, a desaparecer, com o surgimento de bairros recentemente criados - e, de outro lado, a cidade baixa dos velhos prédios sórdidos que abrem suas portas à prostituição desde o anoitecer. Não é raro que algumas personagens dos romances amadianos possuam casas comerciais na cidade baixa enquanto moram nos bairros ricos da cidade alta." (SALAH, 2008, p. 40)

7 "Desde o início da colonização, os nobres e ricos burgueses se instalaram na parte da cidade alta que assistiria ao nascimento dos bairros do Pelourinho, da Sé, - ou Centro-, do Paço. Os prédios ricos que eles edificaram - os sobradões- foram pouco a pouco abandonados para as populações miseráveis e para a prostituição [...] De qualquer forma, a antiga oposição permaneceu, e nos referimos sempre aos bairros ricos quando falamos da cidade alta, mesmo se isso diz respeito apenas a bairros como Campo Grande, Vitória ou Graça. (SALAH, 2008, p. 40)
} 
dialética da malandragem para a dialética da marginalidade ${ }^{8}$, lida com esses vestígios, nos romances atuais, quando são reconduzidos para o tecido literário blocos memoriais, ainda marginalizados, que a história cultural oficial tem dificuldades em decodificar e recodificar em termos de textos não apenas baianos, mas nacionais.

A evocação do termo "texto" leva à esfera conceitual da semiosfera". A atenção voltada ao espaço urbano como rede de significados diversos está na origem da geopoética das semiosferas, o que se poderia ver como uma tentativa de se valorizar espaços periféricos perante um centro hegemônico proposto por uma arquitetura determinada. O «texto» é uma sistematização de uma cultura que permite seu diálogo com outra. Textos novos surgem nos limites das periferias, organizadas menos formalmente que os centros, onde estão as estruturas mais fortes, construções mais arraigadas de todas as culturas ou sistemas. E textos novos na semiosfera soteropolitana, relacionada com a Baía de Todos os Santos e o seu Recôncavo ${ }^{10}$, configuram uma geopoética urbana que pretende-se captar nas análises.

Temos abordado visões da cidade Montreal, na literatura quebequense contemporânea, através do enfoque da semiosfera (SOUZA, 2015a, 2017) que preconiza um centro normativo de sociabilidade e cultura, pressionado pelos centros periféricos, cujas fronteiras funcionam como verdadeiros loci de transformação de linguagens. Na presente abordagem de uma possível geopoética soteropolitana, opta-se por seguir os

\footnotetext{
${ }^{8}$ Lima (2007, p. 71) discorre sobre o embate ideológico entre os malandros e marginais, explorando as faces destas duas figuras que interagem de forma fundamental para a compreensão de um sujeito nacional nesses textos do realismo brutal: o malandro, uma identidade já clássica para se pensar o Brasil, e o marginal, identidade repudiada, mas muitas vezes admirada por segmentos da sociedade brasileira atual. O ser malandro é compreendido como um simples desvirtuamento de caráter, mas, sobretudo como um feixe complexo de ações contraditórias que são aceitáveis porque não causam esões tão graves à população. Esse tipo de malandragem dialética já tinha sido observada por Antonio Cãndido (1993 apud LIMA, 2007), a propósito do romance Memórias de um sargento de milícias, de Manuel Antônio de Almeida. Mas, durante todo o século XX, a situação do malandro marginal foi se tornando mais complexa e esta figura social se viu obrigada a formar novos tipos de grupamento em territórios de favelas. Malandros, fora do mundo do trabalho foram formando gangs nas favelas (SOUZA, 2013), e legiões de retirantes, expulsos do campo pelas secas, vieram igualmente engrossar as fileiras do lupemproletariado nas zonas urbanizadas do país que passaram a ser palco de um novo tipo de banditismo, as quadrilhas do tráfico de drogas, grupos perigosos que, diferentemente dos malandros da sobrevivência, produzem lesões na sociedade.

${ }^{9}$ A semiosfera é um conceito do russo luri Lotman (1996), da Escola de Tártu-Moscou. Foi criado em analogia com o conceito de biosfera, para indicar a interação de sistemas semióticos, de natureza cultural, em lugares e territórios circunscritos pelos analistas. Explicaremos o conceito mais adiante.

${ }^{10}$ Além das fronteiras do Recôncavo, surgem os textos culturais diferenciados do sertão.
} 
questionamentos formulados pelo grupo La Traversée (atelier québécois de geopoétique), liderado principalmente por Rachel Bouvet e l'écrivain-flâneur André Carpentier.

Na obra Ville et Géopoétique (2016), as questões se apresentam da seguinte forma: 1. Cidade e geopoética são termos compatíveis?; 2- Como adotar uma visão poética diante de um espaço considerado, muitas vezes, sujo, violento, barulhento, poluidor e desumano?; 3- Como encarar poeticamente as formas do " habitar » na cidade, levando-se em conta que a maioria das construções são realizadas por especulação imobiliária sem respeito ao ambiente?; 4- A geopoética não deveria adotar apenas uma visão crítica, radical, mostrando que é impossível existir uma cidade sonhada, idealizada, agradável, com a qualidade de vida desejada? ; 5- Finalmente, existem relações sensíveis entre a terra e um meio urbano determinado?

Responder a essas questões não é uma tarefa das mais fáceis. Mas vamos tentar observar, em um corpus selecionado pouco a pouco, como se confrontam a ética burguesa do espaço organizado, o comportamento marginal espraiado em várias outras comunidades como territórios desordenados (que não se acomodam mais na cidade baixa apenas), os mundos dos trabalhos informais e formais, a vivência com os saberes ancestrais fragmentados, as dialéticas entre gritos e silêncios que espelham a evolução de dadas relações de poder e dominação.

\section{Um pouco de justificativa}

Nosso projeto, como já dissemos, dá continuidade, no âmbito das linhas de pesquisa das relações Literárias Interamericanas e da Geopoética, aos estudos comparados e transculturais com ênfase para a literatura brasileira. Primeiramente, é necessário notar as observações que Eduardo Assis pronunciou em uma conferência, em Berlim, em 2012, de que a literatura, só é considerada nacional, quando é produzida no eixo Rio-São Paulo. Se não, permanece adjetivada como literatura estadual, como baiana, gaúcha, mineira, etc. Nesse caso, é uma perspectiva original a de contemplar as representações da cidade de Salvador em uma ficção produzida ou não na Bahia, dando-lhe dimensão nacional e mesmo continental, projetando- a na esfera das relações interamericanas. Por quê começamos a dizer que as representações literárias de Salvador pararam em 1970, com Jorge Amado, e 
que os estudos continuam a averiguar os "capitães de areia», em uma época em que a conjuntura político-social já se apresenta modificada e a cartografia da cidade bastante transformada? É que não existe exatamente uma consideração de toda uma ficção tida como «literatura baiana», sem amplitude nacional, e que, portanto, espelha uma Salvador atual e contemporânea com suas figuras marginais modificadas, seus textos formadores atualizados, que podem acrescentar imagens riquíssimas à história cultural da urbanidade no país.

Mencionamos várias vezes o campo conceitual da história cultural oficial, e não vamos desenvolvê-lo, neste instante, lembrando apenas que ele amplia o território das reflexões impondo uma polissemia estruturante na compreensão das atividades memoriais que selecionam fatos para as representações, mas omitem outros, considerados sem relevância. No mesmo caminho, mencionamos o conceito de «memória longa», a partir da obra de Zila Bernd, a qual afirma que pesquisas para captar os movimentos de formação de um resgate memorial mais prolongado são menos numerosas. De acordo com esta autora, uma "memória de longa duração heterogênea" surge do entrelaçamento de memórias subterrâneas e fragmentárias, cujos vestígios vêm à tona através da palavra poética, ponto de convergência de memórias, silêncios e esquecimentos.

Estima-se que um estudo das literaturas, que põem em cena mobilidades culturais e diásporicas, mostra como são desafiadas as fronteiras delimitadas dos centros das semiosferas que surgem em contextos de transação relacional com maior impacto sobre os leitores pela pluralidade de visões de mundo que veiculam. Considera-se igualmente que os silêncios podem ser reveladores, na medida em que determinadas memórias atravessadas pelos valores da ancestralidade negra, por exemplo, não emergem nos textos oficiais quando se trata de construir a identidade política e cultural brasileira.

Vê-se então que a originalidade da presente pesquisa e justificativa maior de seu desenvolvimento está em captar, primeiramente, uma memória de longa duração que surge no prolongamento das representações da cidade de Salvador, atravessada de tradições e saberes seculares, como primeira capital. Considera-se que a negligência de muitas narrativas, tanto no plano estadual, como no plano nacional, deixa escapar uma série de conflitos que se materializam na semiosfera soteropolitana, composta pelo entrelaçamento de 
inúmeras linguagens. Esta série de conflitos autoriza uma percepção espacial da cidade e a sua renovação no tempo. Os textos da semiosfera dão forma e conteúdo a este espaço urbano específico, traduzindo os princípios de entendimento e organização de um mundo produzido histórica e socialmente. Neste sentido, buscamos, em um segundo momento, identificar as construções geopoéticas que tomam a cidade como elemento central da narrativa e compõem uma representação do urbano. Tentamos resgatar textos que encontram ressonância não apenas no estado da Bahia, mas no Brasil, constituindo-se em pontos de referência para os escritores nacionais responsáveis pela construção de uma visão literária da cidade.

O objetivo geral da pesquisa é então analisar formações geopoéticas de uma série de narrativas romanescas ambientadas na cidade de Salvador, suscetíveis de construir uma memória longa, com base na recuperação de linguagens oriundas de blocos memoriais em circulação na semiosfera urbana da Bahia.

\section{Pressupostos teóricos}

\section{Semiosfera, fronteiras, semiótica da cultura.}

Um estudo de semiosferas se consubstancia, se contextualiza e se instrumentaliza na observação de confrontos de culturas heterogêneas em um espaço e tempo determinados. A semiosfera, que já identificamos como um conceito do russo Iuri Lotman (1922-1933), comparece no cenário socialhistórico como uma construção sígnica que envolve, em sua base - das periferias ao seu centro - modos de existência de linguagens, comandos de imbricação, protocolos de transferência e várias modalidades de ressemantização.

A semiótica da cultura lotmaniana se formou na Universidade de Tártu (Estônia), no contexto dos estudos empreendidos pela Escola Semiótica de Tártu-Moscou. Um dos traços mais característicos da Escola é a bicentralidade. A presença de dois centros, como se sabe, é um traço característico da cultura russa como, por exemplo, a coexistência de Kiev e Nóvgorod na Rússia antiga e de Moscou e São Petersburgo (Petrogrado, Leningrado) no Império Russo e na Rússia moderna.

No âmbito dos estudos linguísticos e literários, a semiótica da cultura se desenvolve concomitante aos estudos do Círculo Linguístico de 
Moscou (1915-1924) e da OPOIAZ (1916-1926) de Petrogrado. O centro de Moscou, mais numeroso, inclue pesquisadores jovens e iniciantes, mas que depois se tornam renomados, entre eles Vladímir Todorov, os irmãos Boris e Vladímir Uspiénski, o folclorista Serguei Nekliúdov, etc.

Mas a semiótica da cultura lotmaniana fixar-se-á como método inédito de averiguação na década 1960-1970, quando ocorre a formação dos principais conceitos. O conceito "texto" deixa de ser aplicado apenas para diferenciar o "texto linguístico" do "texto literário" (como ocorre em Estrutura do texto artístico de 1970), é ampliado e passa a abarcar as mais variadas manifestações da cultura humana, o que resulta na consolidação da noção de "texto da cultura". Justamente nesse segundo período da sua obra, surge o conceito central, a semiosfera, dentro do qual a fronteira desempenha uma função fundamental.

As margens da semiosfera tornam-se, portanto, um espaço de extrema importância. É nesse contexto que surge a noção lotmaniana de "fronteira". Trata-se, naturalmente, de um divisor imaginário que permite a troca de informações entre a semiosfera e o espaço que a circunda. $\mathrm{Na}$ semiosfera, a fronteira tem suas funções: o seu objetivo é limitar a invasão incontrolável dos elementos "alheios", como também filtrar e adaptar tais elementos para a linguagem de uma semiosfera dada. Se o espaço culturalizado de uma semiosfera é visto, por seus integrantes, como ordenado, organizado e seguro, o espaço externo pode ser percebido como desorganizado e caótico, e mesmo como uma não-cultura. O "nosso" e o "alheio" costumam ser constituídos de jeito espelhado, segundo Lotman, de forma que o que é proibido em um espaço é permitido em outro.

A semiosfera é percebida como um conjunto homogêneo, mas é formada por diversos textos que interagem entre si por meio das diferentes linguagens da cultura (música, pintura, literatura e assim por diante). A heterogeneidade interna é uma condição mínima para a existência da semiosfera dentro da qual agem forças centrífugas e centrípetas entre o centro e suas fronteiras. A semiosfera é assim um lugar extremamente dinâmico, no qual costumamos identificar "cronotopos" (BAKHTIN) que se imbricam, e favorecem o ambiente para constantes diálogos em que os textos culturais se multiplicam e ficam disputando o lugar central. Exemplos: a escola, como cronotopo interno (SOUZA, 2016), as ruas como cronotopos externos fronteiriços (SOUZA, 2017). 
No que tange à investigação propriamente literária, a heterogeneidade interna na dinâmica dos cronotopos em fronteiras, a questão pode, com efeito, cruzar os debates sobre a natureza de um "novo realismo" brasileiro, em uma época em que a estética literária tende a uma deslinearização referencial nas correntes pós-modernistas. Este "novo realismo", com os "quadrilheiros" e "bichos-soltos" heroizados, caracterizado como feroz ou brutal, desenvolve-se mais nas fronteiras dos cenários semiosféricos. Nesse sentido, as articulações entre a ficção e a realidade parecem revigorar os princípios criativos do realismo-naturalismo em suas formas de dirigir o olhar para as condições físicas das periferias urbanas.

Muitos estudiosos da literatura brasileira contemporânea destacam, então, a consolidação de uma Literatura marginal, importante não apenas para o mercado editorial, como igualmente para a indústria cultural de filmes e documentários. Citando alguns, lembremos de Beatriz Jaguaribe (2010) que observa que as novas estéticas realistas não repetem necessariamente os cânones do passado, e sim delineiam uma prosa ágil na qual o mundo dos personagens é dinamizado pela ação e pelas falas, em detrimento de longas descrições do ambiente, e essas falas pluralizadas enfraquecem igualmente a autoridade do narrador realista onisciente.

Já Tânia Pellegrini (2008), pela observação das obras de Paulo Lins, Ferréz e Dráuzio Varela, reflete sobre um retorno do trágico (embora com um certo barateamento pela indústria cultural), provocado pelo projeto vitorioso de inserção do país no circuito do capitalismo avançado, que traduz a realidade em ficção em termos de violência praticada por aqueles que estão premidos pela escassez e pela falta. Nesse contexto, conclui a autora, o realismo, que rege este tipo de literatura marginal, não pode ser caracterizado de forma simplista como signo de atraso estético ${ }^{11}$, mas sim como uma postura e um método, cada vez mais em uso, aptos a revelar a função e o valor de boa parte da produção ficcional do Brasil contemporâneo.

\footnotetext{
${ }^{11}$ Antonio Cândido (1989) justifica essa tendência realista-naturalista por uma demora cultural. O Brasil ainda tem problemas de ajustamento e de luta com seu meio, e problemas ligados à diversificação racial, tendo, assim, prolongado suas preocupações naturalistas.
} 


\section{Geopoética}

É Kenneth White quem funda em 1989 o Instituto Internacional de Geopoética para estimular as pesquisas neste campo. De uma forma bem simples, podemos dizer que a geopoética visa desenvolver uma relação sensível e inteligente com a Terra. A Bienal do Mercosul de 2011 - Ensaios de Geopoética - e a Trienal da Tate Britain de 2009 - Altermodern - são exemplos marcantes de exposições internacionais que privilegiaram trabalhos de arte "geopoéticos". Ou seja, que propõem relações (de indivíduos) com determinados territórios.

Segundo Bouvet (2012), a geopoética passa por inúmeros territórios. Enquanto campo de pesquisa e criação transdisciplinar, a geopoética descompartimentaliza disciplinas como a geografia, a literatura, a filosofia, as artes, as ciências da terra, etc. Uma configuração como a do Arquipélago geopoético envolve uma travessia de territórios como as pequenas ilhas situadas em diferentes lugares do planeta. Em geopoética, é interessante se pensar na travessia de diferentes territórios geográficos e culturais, exatamente, como se pode fazer na semiosfera.

A geopoética pressupõe um desejo de abrir espaços circunscritos pelas ideologias, crenças e políticas culturais muito cerradas, a fim de apontar os movimentos e as metamorfoses do mundo efetuados pelos humanos. $\mathrm{O}$ primeiro sentido da natureza, o tipo de afeição, característico da geopoética, pode ser designado, em primeira instância, como a "sensação do mundo": pesquisa de uma linguagem para o mundo, que não subtrai as coisas de sua "mundeidade", ao contrário, as aproxima. A função estética deste enfoque preconiza a formação de uma rede de sentimentos, saberes e poderes sobre o espaço habitado e a possibilidade de sempre mostrar novas formas de apropriação dos territórios habitáveis. Ela segue o ideário de Spinoza sobre a extensão dos sentidos- vista, olfato, audição, tato - de um corpo em movimento em uma situação espacio-temporal determinada. A geopoética instaura uma reorganização simbólica, permitindo a uma subjetividade corporal efetuar sua aprendizagem sobre o espaço, ligando afeição e intelecto, saber e sabor, dinâmica fundamental de pensamento e contemplação.

Todo tipo de mobilidade cultural favorece a composição de recursos geopoéticos, no sentido de impulsionar as relações entre um ser humano e o espaço onde ele age. Da aliança entre geo e poética deve surgir um mundo a 
habitar, pois um novo território emerge, no qual cada um pode respirar a plenos pulmões, engrandecer seu ser, estabelecer relações harmoniosas com os outros à base de um pertencimento comum, um vasto campo de pesquisa e criação no qual se cruzam as ciências, as artes e a literatura (BOUVET, 2012). Trabalhamos o sentido geopoeta de Euclides da Cunha e escritores canadenses, da mesma época, em Traversées géopoétiques: Métis des sertões et de l'ouest canadien (2011), e as tendências da geopoética urbana em Figures spatiales de Montréal. Pour une geopoétique interaméricaine (2017).

Como o disse Pesavento (2002, p. 40) os discursos literários que tem traduzido o sentimento da metrópole ou "cidade aberta" falam sobretudo da mobilidade social, do formigamento, do "mélange de diferentes estratos sociais num mesmo espaço". Assim, é possível, que cada abordagem das imagens e discursos sobre cada espaço urbano brasileiro possa não ser só lido e entendido como uma matriz singular específica de um território, mas funcione como uma metonímia, apesar de suas idiossincrasias, dos processos de urbanização do país, envolvendo os fenômenos de "representação fantasmagórica da cidade" (BENJAMIN, apud PESAVENTO, 2002, p. 30).

A fantasmagorização está associada à visão marxista de Benjamin, de fetichismo de uma mercadoria, que conduz à esfera do sonho e da alienação, capaz de ocultar os contrastes vivenciados pela cidade moderna. A polissemia e a polifonia de nossas cidades míticas e fantasmagóricas podem ser contempladas por uma série de estratégias de "mobilidades culturais", tais como apresentadas no dicionário, organizado por Zila Bernd (2010), no qual movimentos como os da deriva, errância, deslocamento, diáspora, etc., são evidenciados. Aí não falta, evidentemente, a figura do flâneur (BORDINI, BERND, 2010, p. 211-226), responsável pelo mapeamento das cidades modernas, desde Baudelaire, encarnando-se como diferentes caminhantes, até o tipo mauvais flâneur de Popovic (1992). Este perambula pelas ruas de Montreal, desde a primeira metade do século XX, mostrando a situação de miséria dos canadenses franceses, que vão perdendo seus lugares de memória, diante do mundo de business dos canadenses ingleses. O mauvais flâneur, presente em boa parte da literatura quebequense contemporânea (SOUZA, 2017), torna-se apto a empreender textos de geopoética na então contraditória semiosfera montrealesa.

Segundo Bouvet, a geopoética não pressupõe, de forma preponderante, a representação de uma nação, de uma etnia ou de uma 
ideologia particular; ela instrumentaliza o analista para enfatizar os deslocamentos físicos, na obra, sublinhando igualmente as dimensões interiores, culturais e ontológicas que a eles se associam. Por isso, a projeção dos pressupostos da geopoética na observação das semiosferas marca o desejo de insistir na sociosemiose do espaço. Uma tal projeção não demonstra senão o quanto a sociosemiose plena de uma poética do espaço, com uma linguagem dotada de identidades plurais, de pertencimentos variados, de imbricações de memórias próprias dos movimentos dialéticos caminhar/habitar, compreende um repertório simbólico organizado pela cultura do locus socialhistórico em que se desenvolvem a socialização e a interação dos indivíduos. Evidentemente, na movimentação dos mauvais flâneurs, excluídos das partes "nobres" do urbano, na fantasmagorização das cidades, a sociosemiose da interatividade geopoética implica, como linguagem, a decodificação das forças semiosferas.

\section{A eternidade e o desejo}

Estamos montando um corpus ampliado de romances, a partir dos anos 1980, até hoje. Mas, para apresentar uma pequena ilustração neste texto, escolhemos A eternidade e o desejo de Inês Pedrosa. Esta é portuguesa de Coimbra e a obra é a sua primeira ambientada no Brasil. Clara, a personagem principal, é uma portuguesa que retorna anos depois a Salvador, após ter vivido uma experiência traumática na cidade. Foi atingida por um tiro que não deixou uma cicatriz visível no rosto, mas causou um dano irreversível: ela se tornou deficiente visual.

Recordas-me que vou voltar a Salvador. E que vou contigo. Vou ao teu lado, sim. Acredita que te agradeço a gentileza da companhia.Mas tu não pertences ali. E eu tenho um bocadinho de medo de me perder. Então peçote que me contes tudo, Sebastião.

- Tudo? Mas o que é tudo? Tudo o que vejo?- perguntas, num sussurro. Como se, de súbito, te sentisses esmagado pela intraduzível vastidão do teu olhar. O que se vê nunca se pode narrar com rigor. As palavras são caleidoscópios onde as coisas se transformam noutras coisas. As palavras não tem cor - por isso permanecem quando as cores desmaiam. Percebo o teu aturdimento: como se traduz a visão? (PEDROSA, 2008, p. 13)

Esta cidade será o cenário de toda a narrativa principal, mas são os olhos de "outrem", de Sebastião, que devem guiar a personagem cega. São 
estes olhos que deverão nomear os lugares e os objetos que configuram a semiosfera da cidade para Clara. O verbo "transformar" mostra inclusive como a visão desdobrada do guia evidencia-se capaz de romper aquelas estruturas rígidas de sentidos binários, para multiplicar os significados do mundo. As "palavras permanecem" e as "cores desmaiam" são as metáforas potentes suscetíveis de abrir as descrições espaciais que poderão enriquecer uma percepção de vida sem o prisma normal de uma visão. Assim, neste percurso mais audível do que visual, inicialmente, Clara ouve os apelos do padre Antonio Vieira.

No trabalho que fizemos sobre as figuras geopoéticas de Montréal, estabelecemos vários tipos de espaços apropriados às trocas mencionadas. Um dos espaços chama-se "espaço-dobradiça". É o espaço de contacto, onde os grupos de personagens interagem e descobrem as esferas sígnicas de cultura do outro. É o vaivém das periferias permitindo a textualização das memórias interculturais fundadas nos múltiplos pertencimentos. Sebastião se torna o contacto privilegiado para Clara descobrir a semiosfera soteropolitana.

- Peço-te que me mostres o nosso quarto, Sebastião. O nosso quarto, sim, repetes. O roupeiro ao lado direito da porta, a casa de banho ao lado esquerdo. Assim, não, Sebastião. As palavras não servem nesse caso. Leva-me pela mão a cada coisa, deixa-me enumerar os passos, situar-me. Não precisas de dizer, nada, mostra-me só com a mão. Devagar. Para que eu aprenda a reconhecer os cantos e a mobília. (PEDROSA, 2008, p. 40).

E é pela mão que o guia leva a personagem a descobrir inicialmente o espaço íntimo, o espaço habitável, no qual ela deverá se acomodar na cidade. É o local da força centrípeta pronta a concentrar as pequenas referências de uma reterritorialização da qual a personagem necessita para, em seguida, desdobrar sua percepção dos múltiplos lugares da cidade. O importante é que essa escrita de reterritorialização transforma a paisagem literária do espaço urbano soteropolitano ao introduzir lugares-de-textos como múltiplos centros de referências abertas ao conhecimento de cruzamentos culturais e de história da cidade que inauguram novas formas de apreensão de um real desconhecido ou ignorado por boa parte da população.

Descrevo-te o dia: esta manhã vamos visitar o único castelo medieval da América, o castelo Garcia D’Ávila. E depois seguimos para a Praia do Forte, perto do Castelo, onde fica a sede do projeto Tamar [...] E começa a narrar, 
no tom monocórdico de quem decorou, à maneira da tabuada, uma longa lista de nomes e datas, que Garcia D'Ávila era homem de confiança de Tomé de Souza, o primeiro governador-geral do Brasil, vindo a implantar em Salvador, em meados de 1551, a primeira fazenda da então colônia , construindo, em local estratégico para a observação do litoral, uma fortificação única em seu estilo nas Américas. (PEDROSA, 2008, p. 49).

Dir-se-ia que o espaço-dobradiça, configurando o contacto, permite a Clara e Sebastião de percorrer os locais preponderantes da cidade, em uma espécie de city tour. Os deslocamentos são fatores relevantes dos dois amigos que vão criando um texto cartográfico da cidade de Salvador. Eles visitam a igreja do Bonfim, a de São Francisco, o Centro Histórico, terreiro de candomblé, e vários locais atravessados de história, que funcionam como cronotopos. Existe consenso que o modelo de relato de travessias, cronotopo narrativo de longa tradição na cultura íbero-americana, serve para catalogar o universo fictício de uma terra que passa a construir um longo processo de independência histórica e estética. Neste caso, o cronotopo da travessia, fazendo emergir um texto explicativo da semiosfera soteropolitana, revela uma nova viagem de Portugal (através da personagem Clara) à antiga capital de sua maior colônia, através dos discursos daquele que teria sonhado a instauração do V Império: o padre Antonio Vieira, no século XVII, com sua crença messiânica milenarista ${ }^{12}$.

Mas os olhos de Sebastião servem para dar corpo audível e tátil às palavras que Clara tem que decodificar pra entender sua travessia na semiosfera que foi configurada pelo padre Antonio Vieira. Este é o que chamamos de espaço-matrioska (espace gigogne (SOUZA, 2017)), que leva os esboços de textos iniciados no espaço-dobradiça, do contacto, a se superporem em espaço de verdadeiro armazenamento de informações. O armazenamento segue os princípios de formação de interdiscursos e de intertextualidades que governam as estruturas das narrativas contemporâneas. A simultaneidade temporal, localizada em determinados espaços da semiosfera, desvenda a natureza relativa do tempo em um sistema

\footnotetext{
12 Portugal seria o Quinto Império, após os assírios, persas, gregos e romanos.Seria uma forma de legitimar o movimento autonomista português, que conseguira o fim da União Ibérica. O mito do sebastianismo preconiza que o infante Dom Sebastião, morto na batalha de Alcácer-Quibi, em 1578, essuscitaria para reinar no Quinto Império. O sebastianismo foi muito utilizado nas crenças dos sertanejos de Canudos que lutavam contra as forças do exército brasileiro, no final do século XIX.
} 
de referências em diálogos dinâmicos, equiparando num mesmo nível narrativo registros mnemônicos dos centros e das periferias.

A construção dos personagens que enunciam os relatos e produzem os espaços-matrioska revela hibridez em suas configurações narrativas. Este espaço de armazenamento marca sensivelmente a orientação metalinguística da obra e envolve uma concepção autoreferencial em que o tempo aglutina visões memoriais plurais e complexas, mais que encadear fragmentos lineares de ontem, hoje e amanhã. Com a visão de Sebastião, Clara formata palavras, atribui a elas cores, e configura seu caminho, munida de trechos dos Sermões de Antonio Vieira.

Por princípio, creio em tudo, Sebastião - dá-me jeito. Onde eu disse Deus podes ler Razão, ou Amor - o tal que ilumina e ensombra a alma, ao mesmo tempo, Sem Deus, Vieira não teria chegado aos devaneios nacionalistas a que chegou; mas também não teria atingido o ãmago da compaixão humana, que faz com que ainda hoje as suas palavras caminhem diante do tempo.

Os Filósofos dizem que uma contraditória não cabe na esfera dos possíveis, eu digo que cabe nas esferas dos olhos. (PEDROSA, 2008, p. 61).

Clara reflete, pensa na iluminação das palavras, a partir das descrições visuais de Sebastião. Os trechos de Vieira seguem sempre suas considerações sobre o ato de nomear o mundo e de abstrair idéias em negrito, como citações intertextuais realmente heterogêneas. Esta noção autoreferencial do espaço-matrioska como síntese de cronotopos estéticos de uma semiosfera determinada é expressiva de um universo simbólico em que tempo histórico e tempo mítico não conseguem estipular fronteiras. Por esse caminho, Clara consegue conjeturar as visões de Vieira sobre o V Império, sobre a sensibilidade dos índios, suas idéias sobre a Companhia de Comércio de Portugal com o Brasil, suas reticências sobre a escravidão, etc., e ao mesmo tempo projetar tais visões sobre a vida soteropolitana contemporânea com o sincretismo religioso dos orixás e santos católicos.

É muito original no espaço-matrioska o fato de que temporalidades com suas ideologias, crenças e valores possam conviver legitimados nos cronotopos estéticos do uso da palavra: "Palavras que lavram a terra e revolvem de luz os meus olhos sepultados. Palalavras, titubeantes." (PEDROSA, 2008, p. 49). O cronotopo estético do espaço-matrioska é modelo habitualmente associado à busca de identidade espacial, ou mesmo 
semiosférica, na medida em que seu exercício conduz os personagens a certo reconhecimento da história dos locais (urbanos ou não) em expressões integradoras. A legitimação de tais cronotopos situados nos interstícios de vários universos simbólicos articula as histórias narradas em torno das expressões metalinguisticamente explícitas dos deslocamentos, relatos de aprendizagem, e armazenamentos sígnicos que os personagens efetuam.

Já reconhecemos, em outros trabalhos (SOUZA, 2017), um terceiro tipo de espaço, que é o serpentina. Este marca topologicamente um movimento de exploração espacial apto a configurar a semiosfera com seus centros e periferias. Como funcionam os diálogos entre os textos das periferias em suas forças centrípetas destinadas a atingir o centro? Em $A$ eternidade e o desejo, já dissemos como Clara se desloca pela cidade de Salvador. A escrita, que vai adquirindo uma extraordinária centralidade no romance, ocupa o fio condutor na ficção como em uma serpentina. No caminho e no processo de criação, Clara gira pela semiosfera soteropolitana:

Aproxima-se a hora do almoço, na praia de Guarajuba [...] Marcos reúne o grupo para anunciar que nos levará esta noite a uma sessão de candomblé, na Casa Branca, o terreiro de candomblé mais prestigiado da Bahia... (PEDROSA, 2008, p. 55).

Estamos a chegar ao alto da Colina Sagrada, Clara, à famosa Igreja do Senhor do Bonfim. Dizes que ouves um coro de mulheres. Cantam alto. Cantam com força. (PEDROSA, 2008, p. 68).

Entramos no sagrado terreiro da Casa Branca do Engenho Velho, e Marcos desaparece. Edson, o guia alternativo, explica-nos que o Terreiro é de Oxossi, o orixá da mata, caçador que garante o sustento de sua tribo, o e o Templo principal é de Xangô, o tal antigo rei de Oyó. (PEDROSA, 2008, p. 71).

A eternidade e o desejo são duas coisas tão parecidas, que ambas se retratam com a mesma figura. Os egípcios, nos seus Geroglíficos, e antes deles os caldeus, para representar a eternidade pintaram um $\mathrm{O}$, porque a figura circular não tem princípio nem fim; e isto é ser eterno. $\mathrm{O}$ desejo ainda teve melhor pintor, que é a natureza. Todos os que desejam, se o afecto rompeu o silêncio, e do coração passou à boca, o que pronunciam naturalmente é O. (Pedrosa, 2008, p. 76).

As imagens dos personagens que circulam são referências imprescindíveis quando se tenta captar a circularidade das forças centrípetas aptas a modificar um centro semiosférico. Guarajuba-Bonfim-Casa Branca, oceano-catolicismo-candomblé, cronotopos culturais que vão sendo imbricados pelos passos redobrados dos personagens; passos que circulam em 
figuras de eternidade, giram, buscam um encontro com uma identidade semiosférica, marcado por um tempo integrador de conhecimentos adquiridos durante os séculos. Os personagens itinerantes se movem em círculos, recompondo fragmentos de vários imaginários que se entrecruzaram capazes de formar um novo centro mestiço da primeira capital do Brasil. Estará no mundo mestiçado de Portugal, África e América ameríndia o novo centro do V Império?

O que fica bastante claro neste exemplo de geopoética urbana, que fala de violência, colonização, dominação e superposição de culturas, é que é possível tratar do espaço, como esfera semiosférica, de circulação de signos, com um enfoque estético nos passos recobrados de Clara e de seus companheiros. Esta semiosfera revela-se como a imagem circular da eternidade, contendo a epifania das mestiçagens.

O espaço-matrioska é o espaço da memória cumulativa, do armazenamento. É o repositório de conhecimento que vem a ser realocado, e, muitas vezes, reestruturado. Clara volta a Salvador e guia-se por textos sacros e sermões de Antonio Vieira, visitando igrejas barrocas e terreiros de candomblé, mercados e o Pelourinho. Este espaço cumulativo permite a instauração da memória longa e mesmo a revelação de memórias transoceânicas. Já o espaço-serpentina é o espaço de realinhamento das memórias e das histórias a eles relacionadas. Clara gira na cidade, como em uma serpentina, flagrando vestígios e marcando com traços, delineando, episódios presentes e esquecidos da história de Salvador. Constrói e desconstrói os dispositivos de fronteira, os vértices de controle de passagem, permitindo alcançar uma apropriada síntese epistemológica das características estruturais da memória longa em curso.

Este é um exemplo de espaço que demarcamos para facilitar a averiguação das imbricações interculturais em uma geopoética em sociosemiose. Evidentemente, não há hierarquia entre espaços e cronotopos que existem apenas para capitanear e integrar um cerimonial dinâmico de possibilidades, acessos a sintonias virtuais de semiose.

\section{À guisa de conclusão}

Considerando que este projeto tem como objetivo geral averiguar formações geopoéticas em narrativas sobre a cidade de Salvador, suscetíveis 
de se inscreverem em uma memória longa do país, espera-se que ele traga contribuições profícuas para os estudos sobre as relações entre literatura e espaço. Tais estudos poderão interessar a vários estudantes e pesquisadores das ciências humanas, à medida que evidenciam a dinâmica de construção e desconstrução dos territórios, com seus vetores culturais.

No questionamento sobre a importância da geopoética, a pesquisa será um excelente instrumento para estudantes de urbanismo avaliarem se realmente uma visão poética diante de um espaço considerado sujo, violento e desumano, como a cidade, e em especial Salvador, é capaz de gerar projetos aptos a modificar tal cenário semiosférico. Esperamos igualmente que a emergência de um saber sobre as formações culturais do território soteropolitano possibilite a análise de como encarar poeticamente as formas do «habitar» na cidade, com intersecções produtivas e harmônicas entre cultura, natureza e seres humanos. Acreditamos que se descobre assim, pouco a pouco um conjunto mais amplo da realidade das cidades, o que exige novos olhares sobre as relações sensíveis entre a Terra e um meio urbano determinado.

Contribuindo como grupo de pesquisa local, mas com ramificações nacionais e internacionais, desejamos trabalhar, incorporar e produzir avanços teórico-metodológicos que possam ser apresentados em vários eventos nacionais, a colegas de universidades e a equipes diferenciadas que se interessam sobre as realidades urbanas da semiosfera brasileira com seus principais embates culturais.

Do ponto de vista literário, vemos como o estudo de uma memória de longa duração surge do entrelaçamento de espaços heterogêneos cuja imbricação vem à tona através da palavra poética, ponto de convergência de lembranças, mas igualmente de silêncios e esquecimentos. Um estudo das literaturas, que põem em cena mobilidades culturais mostra como são desafiadas as fronteiras delimitadas dos centros das semiosferas que surgem em contextos de um espaço histórico. Os textos da semiosfera dão forma e conteúdo a um espaço urbano específico, traduzindo os princípios de entendimento e organização que permitem flagrar como se dá os entrelaçamentos de diferentes blocos memoriais que fertilizam as novas narrativas que resgatam e ressemantizam as transformações da urbe soteropolitana e, por via da consequência, brasileira. 


\section{Referências}

Ficção

AMADO, Jorge. Tocaia Grande: a face obscura. Rio de Janeiro: Record, 1984.

AMADO, Jorge. Mar morto. 71. ed. Rio de Janeiro: Record, 1996.

AMADO, Jorge. Capitães da areia. 95. ed. Rio de Janeiro: Record, 1998.

PEDROSA, Inês. A eternidade e o desejo, Rio de Janeiro, Objetiva, 2008.

Obras Teórico-críticas

ALBUQUERQUE, Jr., D. M. A invenção do Nordeste e outras artes. Recife, Ed. Massangana. São Paulo: Cortez Editora, 1999.

BAKHTINE, Mikhail. Esthétique de la création verbale. Paris, 1984.

BERND, Zila. Por uma estética dos vestígios memoriais. Releitura da literatura contemporânea das Américas a partir dos rastros. Belo Horizonte, MG: Fino Traço, 2003.

BERND, Zila. (Org.). Dicionário das mobilidades culturais: percursos americanos. Porto Alegre: Literalis, 2010.

BERND, Zilá (Org.). Dicionário de figuras e mitos literários das Américas. Porto Alegre: Tomo editorial e editora da UFRGS, 2007. 704 p.

BERND, Zilá. (Org.). Insubmissão e mobilidade cultural: percursos americanos. Porto Alegre: Literalis, 2010. No prelo.

BERND, Zilá. Américanité et mobilités transculturelles. Québec: Presses de 1' Université laval, 2009. Coll. Americana.

BISPO, Ma. de Fátima, S., 'Pereba”, In: SOUZA, Licia S. (Org.) Dicionário de Personagens Afro-brasileiros. Salvador: Quarteto Editora, 2009, p. 301-305.

BOUVET, R., Vers une approche géopoétique: Lectures de Kenneth White, Victor Segalen, J.-M. G. Le Clézio, Presses Universitaires du Québec, 2015.

BOUVET, R. (dir.), Ville et Geopoétique. Paris, L'Harmattan, 2016.

BOUVET, Rachel. Présentation. In: BOUVET, Rachel, WHITE, Kenneth (éd.), Le nouveau territoire. L'exploration géopoétique de l'espace. Coll. FIGURA, n. 18, Montréal, 2008. 
BOUVET, Rachel. Pages de sable. Essai sur l'imaginaire du désert, Montréal/Québec, XYZ Éditeurs, coll. « Documents », 2006.

CÂNDIDO, Antonio. A nova narrativa. In: A Educação pela Noite e Outros Ensaios. São Paulo, Ática, 1989.

FONSECA, Rubem. A arte de andar nas ruas do Rio de Janeiro. In: Romance negro e outras histórias. São Paulo: Cia das Letras, 1992.

JAGUARIBE, Beatriz. Ficções do real: notas sobre as estéticas do realismo e pedagogias do olhar na América Latina contemporânea. Ciberlegenda. Niterói. v. 2, n. 23, 2010, p. 6-14. Acesso: 17/06/2015.

LEENHARDT, J.; FIALHO, D. M.; SANTOS, N. M. W.; MONTEIRO, C.; DIMAS, A., (Org.). História cultural da cidade. Homenagem a Sandra Jatahy Pesavento. Porto Alegre: Marcavisual/ PROPUR, 2015.

LIMA, Valquíria. O malandro, o marginal, e a construção da identidade nacional: o mal-estar de Cidade de Deus. In: NOVAES, C.; BOTELHO, M. Seis passeios por Cidade de Deus. Feira de Santana, Editora da Universidade de Feira de Santana, 2007, p. 69-80.

LOTMAN, Youri. La sémiosphère. PULIM, Limoges, 1999.

PELLEGRINI, Tânia. Despropósitos: estudos de ficção brasileira contemporânea. São Paulo: Annablume/Fapesp

ROCHA, João César. Dialética da marginalidade. Folha de São Paulo, 29 de fevereiro de 2004.2 Disponível: http://www1.folha.uol.com.br/paywall/login.shtml?http://www1.folha.uol.c om.br/fsp/mais/fs2902200404.htm. Acesso: 23-05-2015

ROCHA, Tatiana R. D. Cidade de Deus, o arcaico e o moderno no romance contemporâneo.

http://bdtd.bce.unb.br/tedesimplificado/tde_busca/arquivo.php?codArquiv o=1783 Acesso: 19 de junho de 2011.

SALAH, Jacques. A Bahia de Jorge Amado. Salvador: Fundação Casa de Jorge Amado, 2008.

SOUZA, Licia Soares de. Figures spatiales de Montréal. Une geopoétique urbaine interamericaine. Montréal: Société des Écrivains, 2017.

SOUZA, Licia Soares de. Le suicide comme thème formateur d'une mémoire de la nature des sociétés de consommation: analyse de Génération Pendue de Myriam Caron et Cette Terre d'Antônio Torres. Interfaces Brasil/Canadá, v. 15, p. 31-43, 2015a. 
REPRESENTAÇŌES DE SALVADOR NA LITERATURA BRASILEIRA CONTEMPORÂNEA: POR UM MODELO DE GEOPOÉTICA URBANA

SOUZA, Licia Soares de. Infância e errância: imagens da criança abandonada na ficção brasileira. In: Estudos de Literatura Contemporânea Brasileira. $n$. 46, p. 79-103, 2015.

SOUZA, Licia Soares de. Os capitães da areia na construção do território soteropolitano. In: Amerika, Rennes, n. 10, 2014. Disponível em: https://amerika.revues. org/4736.

SOUZA, Licia Soares de. O realismo Pós-metafísico: uma sociedade de exclusão no cinema e na televisão brasileiros. Feira de Santana: EDUEFS, 2013.

SOUZA, Licia Soares de. Les labyrinthes de la nouvelle violence urbaine dans les romans québécois. Revista Eletrônica de Línguas e Literaturas Estrangeiras, v. 2, p. 36, 2012.

SOUZA, Licia Soares de. Géopoétique et Métisssage. In: Transactions Mémorielles et Identitaires: 20 ans d'études canadiennes au Brésil, 2011. Disponível em: http://www.anaisabecan2011.ufba.br/AnaisABECAN1.html, accesso em 20/09/2015.

SOUZA, Licia Soares de. Formas e expressões de uma "nova" violência: Cidade de Deus e Elite da Tropa. In: CARRIZO, Silvina Liliana; NORONHA, Jovita M. G. (Orgs.). Relações Literárias Interamericanas: território \& Cultura. Juiz de Fora, Ed. UFJF, p. 297-315, 2010.

SOUZA, Licia Soares de. Deriva. In: BERND Zila (Org.). Dicionário das mobilidades culturais: percursos americanos. Porto Alegre: Literalis, p. 87108, 2010.

SOUZA, Licia Soares de. Literatura \& Cinema. Traduções Intersemióticas. Salvador: EDUNEB, 2009.

SOUZA, Licia Soares de (Org.). Dicionário de Personagens Afro-brasileiros. Salvador: Editora Quarteto, 2009.

SOUZA, Licia Soares de. Utopies américaines au Québec et au Brésil. Les Presses de l'Université Laval, 2004, (col. Américana).

SOUZA, Ronaldes de Melo. A Geopoética de Euclides da Cunha. Disponível em: http://www.casaeuclidiana.org.be/download/default.asp., accesso em: $12 / 04 / 2003$.

ZALUAR, Alba; ALVITO, Marcos. Um século de favela. FGV: Editora, 1998.

WHITE, Kenneth. Les pérégrinations geopoétiques de Humboldt. Disponível 
http://www.geopoetique.net/archipel_fr/institut/cahiers/cah2_kw.html, Acesso: 10 de out. 2011.

Recebido em 30 de abril de 2018.

Aceito em 28 de maio de 2018. 